\title{
Impact of Carbon Black from Gasoline Engine on Flow of Current
}

\author{
Okparaku. V. I $\mathbf{I}^{1}$, Igbokwe. K. $\mathrm{K}^{2}$, Isu. $\mathbf{J}^{3}$ \\ School of Science and Engineering Technology, Uma Ukpai Polytechnic, Ohafia, Abia State, Nigeria ${ }^{1}$ \\ Department of Physics/Electronics, Abia State Polytechnic, Aba, Abia State, Nigeria ${ }^{2,3}$
}

\begin{abstract}
This research titled "Impact of Carbon Black from Gasoline Engine on Flow of Current" was conducted with objective to ascertain the extent of current flow in a circuit containing carbon black. The carbon black was collected from tailpipe of 5000KVA gasoline generator after the gasoline had undergone deflagration. A simple circuit was set up with the rheostat, voltmeter, ammeter, a 12 -volts battery and a fixed resistor value of $2 \Omega$. The rheostat was adjusted to obtain a suitable value of current and potential difference (p.d) which were recorded as $\mathrm{I}_{\mathrm{o}}=2.14 \mathrm{~A}$ and $\mathrm{V}_{\mathrm{o}}=4.24 \mathrm{~V}$. Herein carbon black was connected to the circuit which showed no readable result of current flow. Afterwards $5 \mathrm{ml}$ of dilute $\mathrm{H}_{2} \mathrm{SO}_{4}$ in $15 \mathrm{ml}$ syringe was connected in series with the fixed resistor and the reading of current and p.d were taken as $\mathrm{I}_{\mathrm{s}}=2.13 \mathrm{~A} \mathrm{~V} \mathrm{~V}_{\mathrm{s}}=4.26 \mathrm{~V}$. Thereafter $0.4 \mathrm{~g}$ mass of carbon black was added to the dilute $\mathrm{H}_{2} \mathrm{SO}_{4}$ and same mass subsequently added in until it summed up to $4.0 \mathrm{~g}$ of carbon black. At each instant of addition of $0.4 \mathrm{~g}$ of carbon black the values of current and p.d were recorded. It was found from the results that the addition of the carbon black to dilute $\mathrm{H}_{2} \mathrm{SO}_{4}$ solution increased p.d and reduced the current flow. This simply implies that carbon contained in the carbon black acted as semiconductor at intrinsic state which also resisted the flow of current when doped with dilute $\mathrm{H}_{2} \mathrm{SO}_{4}$.
\end{abstract}

Keywords: Carbon black, Current flow, Gasoline Engine, Impact

\section{INTRODUCTION}

Electrical resistivity (also known as specific electrical resistance or volume resistivity) is an intrinsic property that quantifies how strongly a given material opposes the flow of electric current. A low resistivity indicates a material that readily allows the flow of electric current. Resistivity is commonly represented by the Greek letter $\rho$ (rho). The SI unit of electrical resistivity is the ohm-metre $(\Omega-\mathrm{m})[1,11]$. Electrical conductivity or specific conductance is the reciprocal of electrical resistivity, and measures a material's ability to conduct an electric current. It is commonly represented by the Greek letter $\sigma$ (sigma), but $\kappa$ (kappa) (especially in electrical engineering) or $\gamma$ (gamma) are also occasionally used. Its S.I unit is siemens per metre $(\mathrm{S} / \mathrm{m})$ [5]. Many resistors and conductors have a uniform cross section with a uniform flow of electric current, and are made of one material [6]. All copper wires, irrespective of their shape and size, have approximately the same resistivity, but a long, thin copper wire has a much larger resistance than a thick, short copper wire. Every material has its own characteristic resistivity - for example, resistivity of rubber is far larger than copper's. The resistivity can be expressed as:

$$
\rho=\frac{R A}{L}
$$

The $\rho$ represents resistivity, R represents resistance, A represents cross section area and L represents the length of the conducting material [2].

A hydraulic analogy, passing current through a high-resistivity material is like pushing water through a pipe full of sand while passing current through a low-resistivity material is like pushing water through an empty pipe. If the pipes are the same size and shape, the pipe full of sand has higher resistance to flow. Resistance, however, is not solely determined by the presence or absence of sand. It also depends on the length and width of the pipe: short or wide pipes have lower resistance than narrow or long pipes [10]. The above equation (eqn 1) can be transposed to get Pouillet's law named after Claude Pouillet:

$$
R=\frac{\rho L}{A}
$$

Another law that best describes relationship among resistance, current and voltage of an electrical circuit is known as Ohm's law represented by:

$$
V=I R
$$




\section{International Advanced Research Journal in Science, Engineering and Technology}

Vol. 6, Issue 4, April 2019

A metal consists of a lattice of atoms, each with an outer shell of electrons that freely dissociate from their parent atoms and travel through the lattice. This is also known as a positive ionic lattice [7]. This sea of dissociable electrons allows the metal to conduct electric current. In semiconductors the position of the Fermi level is within the band gap, approximately halfway between the conduction band minimum and valence band maximum for intrinsic semiconductors. This means that at zero Kelvin $(0 \mathrm{~K})$, there are no free conduction electrons, and the resistance is infinite. However, the resistance continues to decrease as the charge carrier density in the conduction band increases [3]. In extrinsic (doped) semiconductors, doped atoms increase the majority charge carrier concentration by donating electrons to the conduction band or producing holes in the valence band. For both types of donor or acceptor atoms, increasing doping density reduces resistance. Hence, highly doped semiconductors behave metallically [4].

An atom whose valence electron less than four is metallic and conductive; atom with valence electron more than four is a non-metal and an insulator and an atom whose valence electron is four is a semiconductor. Semiconducting materials are atoms like Silicon, Germanium and Carbon because they have four valence electrons $[9,12]$.

Carbon black is virtually pure elemental carbon in the form of colloidal particles that are produced by partial combustion or thermal decomposition of gaseous or liquid hydrocarbons under controlled conditions [8].

\section{MATERIALS AND METHOD}

The following were the materials used the research experiment: Voltmeter, Ammeter, $2 \Omega$ Resistor (Standard), Rheostat, Battery (12 Volts), Connecting wires, Spatula, Weighing balance, Crucible, Carbon black, Dilute tetraoxosulphate(vi) acid $\left(\mathrm{H}_{2} \mathrm{SO}_{4}\right)$, Syringe $(15 \mathrm{ml})$. The carbon black used in this method was produced and collected from tailpipe of 5000KVA generator (a gasoline engine) before the circuit was then set up for the experiment. The ammeter which measures the current flowing through the metallic conductor (conducting material with $2 \Omega$ ) was connected in series with the conducting material, the rheostat and the battery. A Voltmeter was connected in parallel with the conducting material and measured p.d across it. Current was allowed to flow in the circuit by pressing down (closing) the switch. The rheostat was varied to obtain tangible values of current and p.d and their initial values were recorded as $\mathrm{I}_{\mathrm{o}}$ and $\mathrm{V}_{\mathrm{o}}$ respectively. The rheostat was kept constant in the subsequent repetitions.

The carbon black was then first connected in series with the $2 \Omega$ resistor which showed no readable flow of current on the ammeter. The circuit was disconnected and afterwards the process was repeated by connecting another material (syringe containing $5 \mathrm{ml}$ of $\mathrm{H}_{2} \mathrm{SO}_{4}$ ) in series with the $2 \Omega$ material and the values of current and p.d were recorded as $\mathrm{I}_{\mathrm{s}}$ and $\mathrm{V}_{\mathrm{s}}$ respectively. Thereafter, $0.4 \mathrm{~g}$ of the carbon black was added into the syringe containing the $5 \mathrm{ml}$ of $\mathrm{H}_{2} \mathrm{SO}_{4}$, properly shacked and connected again in series with the $2 \Omega$ material. The key was closed and the values of current and p.d were recorded as I and V respectively. The quantities of carbon black were varied at intervals of 0.4 gram for another nine repetitions (up to 4.0 gram of carbon black added) and values of I and V recorded. The mixture of carbon black and dilute $\mathrm{H}_{2} \mathrm{SO}_{4}$ were labeled $\mathrm{X}$ as the results were carefully recorded.

\subsection{Experimental Diagram}

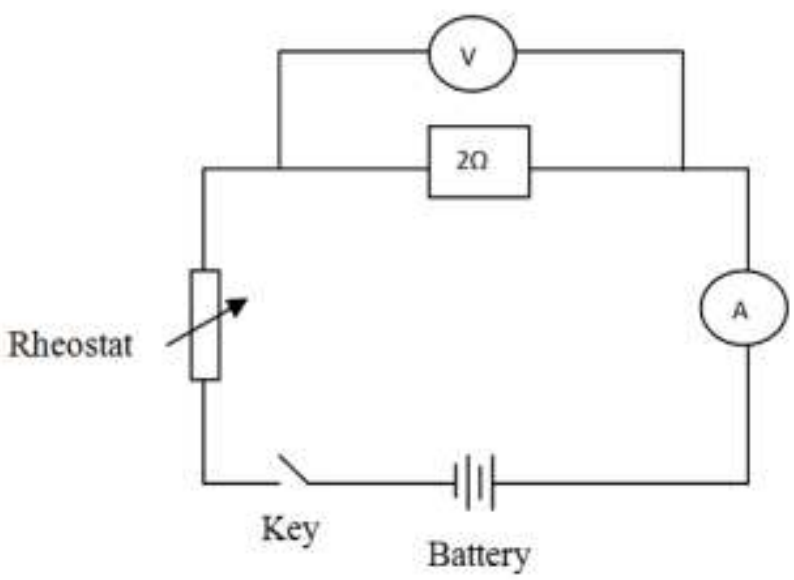

Fig. 1: Circuit diagram of experiment to determine electrical resistance before connecting carbon black. Figure 1 and 2 are the circuitry of the experiment before the addition and after the connection of the mixture of carbon black and dilute $\mathrm{H}_{2} \mathrm{SO}_{4}$ solution respectively. 


\section{International Advanced Research Journal in Science, Engineering and Technology}

Vol. 6, Issue 4, April 2019

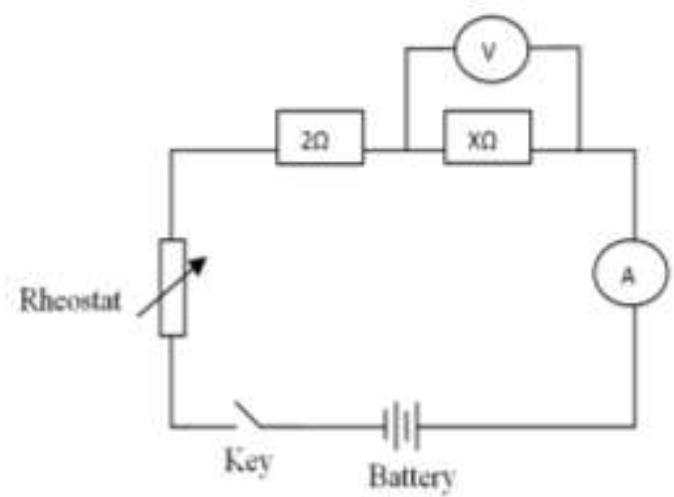

Fig. 2: Circuit diagram of experiment to determine electrical resistance when mixture of carbon black in $\mathrm{H}_{2} \mathrm{SO}_{4}$ was connected.

\section{RESULTS AND DISCUSSION}

The first reading when $2 \Omega$ (fixed) resistor was connected in series with rheostat (variable resistor) gave initial values of voltmeter (p.d) reading and Ammeter (current) reading as $\mathrm{V}_{\mathrm{o}}$ and $\mathrm{I}_{\mathrm{o}}$.

$\mathrm{V}_{\mathrm{o}}=4.24 \mathrm{~V}$

$\mathrm{I}_{\mathrm{o}}=2.14 \mathrm{~A}$

As a $12-\mathrm{V}$ battery was used as voltage source, the voltage in the rheostat was found to be: $\mathrm{V}_{\mathrm{e}}=(12-4.24)=7.76 \mathrm{~V}$ and the current in the circuit is $2.14 \mathrm{~A}$.

The Resistance $\left(\mathrm{R}_{\mathrm{e}}\right)$ of the rheostat at this reading was determined using Ohm's relation, $\mathrm{V}=\mathrm{IR}$ :

$\mathrm{R}_{\mathrm{e}}=\mathrm{V}_{\mathrm{e}} / \mathrm{I}_{\mathrm{o}}$

$\mathrm{R}_{\mathrm{e}}=7.76 / 2.14$

$\mathrm{R}_{\mathrm{e}}=3.66 \Omega$

The $3.66 \Omega$ was set as the standard resistance of rheostat for suitable reading of the p.d and current. This resistance opposed the flow of current by dropping the voltage from $12 \mathrm{~V}$ to $4.24 \mathrm{~V}$. This is about $65 \%$ reduction in voltage of the battery which allowed only $35 \%$ of the voltage to cross the rheostat for suitable ammeter and voltmeter reading.

When only the syringe containing $5 \mathrm{ml}$ of $\mathrm{H}_{2} \mathrm{SO}_{4}$ was connected in series with the $2 \Omega$ material leaving the rheostat unvaried, the values of current and p.d were recorded as $I_{s}$ and $V_{s}$. The current values of $I_{o}$ and $I_{s}$ are almost the same with difference of $0.01 \mathrm{~A}$.

$\mathrm{I}_{\mathrm{s}}=2.13 \mathrm{~A}$

$\mathrm{V}_{\mathrm{s}}=4.26 \mathrm{~V}$

Results of the electrical conductivity of carbon black when added to $\mathrm{H}_{2} \mathrm{SO}_{4}$ were recorded and tabulated against the mass variation as presented in the table below.

Table 1: Variations of p.d $\left(\mathrm{V}_{\mathrm{s}}\right)$ and current $\left(\mathrm{I}_{\mathrm{s}}\right)$ for mixture of carbon black and dilute $\mathrm{H}_{2} \mathrm{SO}_{4}$

\begin{tabular}{|c|c|c|}
\hline Mass, $\mathbf{M}(\mathbf{g})$ & $\begin{array}{l}\text { Potential Difference, } \mathbf{V}_{\mathbf{s}} \\
(\mathbf{V})\end{array}$ & Current, I (A) \\
\hline 0.4 & 3.22 & 1.73 \\
\hline 0.8 & 4.69 & 1.54 \\
\hline 1.2 & 5.06 & 1.22 \\
\hline 1.6 & 5.42 & 1.03 \\
\hline 2.0 & 5.98 & 0.82 \\
\hline 2.4 & 6.14 & 0.51 \\
\hline 2.8 & 6.58 & 0.37 \\
\hline 3.2 & 6.65 & 0.31 \\
\hline 3.6 & 6.72 & 0.25 \\
\hline 4.0 & 7.18 & 0.19 \\
\hline
\end{tabular}

From results in table 1 , it was found that as the quantity of carbon black increased by $0.4 \mathrm{~g}$ in the $\mathrm{H}_{2} \mathrm{SO}_{4}$ solution there was increase in potential difference and decrease in current flow. These results showed that the addition of carbon black (CB) increased the work done by the charge (electron) to move from one end to another end of the conducting wire was increased thereby making potential difference to increase. The result implies transposing Ohm's law (eqn 3) into: 


\section{International Advanced Research Journal in Science, Engineering and Technology}

Vol. 6, Issue 4, April 2019

$$
R=\frac{V}{I}
$$

This relation simply means that as the resistance $(\mathrm{R})$ of conducting material increased, the potential difference between the ends of the conducting wire is increased and electric current flow decreased.

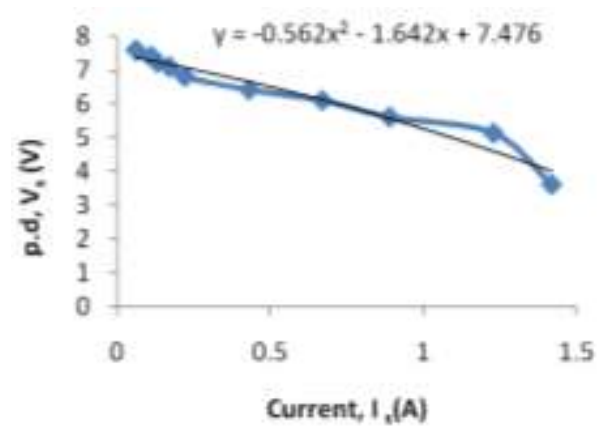

Fig 3: Graph of potential difference (V) versus current (I) of mixture of carbon black in dilute $\mathrm{H}_{2} \mathrm{SO}_{4}$ solution

The graph in Fig. 1 is a negative graph which implies that the potential difference between the ends of the conducting material is inversely proportional to current flowing across the circuit. The non linearity of the graph also indicated the presence of other substances in gasoline apart from carbon and hydrogen that are primarily its constituent substances. Hence, during the deflagration the other substances are also deposited along with unburned carbon inside the carbon black. This affects the feature of the results of the experiment as seen in the graph.

\section{CONCLUSION}

Carbon black from gasoline engine (generator using gasoline) contains unburned carbon substance. This is proven by the impact of the carbon black on the current flow in the electrical circuit used in this research experiment. In the results of table 1 and figure 1 it appeared the carbon black affected the flow of current by increasing the potential difference between the ends of the conducting material and thereby decreased the current flow. The experimental results also depict that carbon acted as semiconductor because it could not conduct electricity when it was connected to the circuit until it was mixed with dilute $\mathrm{H}_{2} \mathrm{SO}_{4}$ solution. Its presence in the mixture of carbon black and dilute $\mathrm{H}_{2} \mathrm{SO}_{4}$ affected the flow of current as compared to when only the dilute $\mathrm{H} 2 \mathrm{SO} 4$ was connected to the circuit. This indicated that carbon black resisted the flow of current in the circuit.

\section{RECOMMENDATIONS}

In electronics study and applications only silicon and germanium are discussed and used disregarding carbon which is also a semiconductor by theoretical implications. Based on the findings in this research it is therefore recommended that effective application of carbon should be implemented in electronics. Also, carbon black from gasoline and generally petroleum should be harnessed for application in electrical and electrical purposes owing that it affects the flow of current like other resisting materials. Hence further researches should employed in finding the proper electrical and electronics properties of carbon black.

\section{REFERENCES}

[1]. Lowrie, "Fundamentals of Geophysics", Cambridge University Press, pp. 254, 2007.

[2]. R. A. Serway, "Principles of Physics", 2nd ed., Saunders College, Fort Worth, Texas, London, p. 602, 1998.

[3]. D. Giancoli, "25. Electric Currents and Resistance : In Jocelyn Phillips, Physics for Scientists and Engineers with Modern Physics", 4th ed., Upper Saddle River, New Jersey, Prentice Hall, p. 658, 1990.

[4]. J. O'Malley, "Schaum's outline of theory and problems of basic circuit analysis", McGraw-Hill Professional, p. $19,1992$.

[5]. N. Kumar, "Comprehensive Physics XII", Laxmi Publications, pp. 282, 2003.

[6]. E. Bogatin, "Signal Integrity: Simplified", Prentice Hall Professional, pp. 114, 2004.

[7]. L. Doug, "Electronics All-in-One For Dummies", John Wiley \& Sons, 2012.

[8]. C. M. Long, M. A. Nascarella, P. A. Valberg, "Carbon Black vs Black Carbon and other Materials Containing Elemental Carbon: Physical and Chemical distinction", Environment Pollution, 2013.

[9]. V. K. Mehta \& R. Mehta, "Principles of Electronics", S. Chand \& Company, Ram Nagar, New Delhi, 1995.

[10]. M.R. Ward, "Electrical Engineering Science", McGraw-Hill, pp. 36-40, 1971

[11]. J. C. Gallop, "SQUIDS, the Josephson Effects and Superconducting Electronics", CRC Press, pp. 3, 1990.

[12]. H. Alice, "Dielectric Strength of Air". The Physics Factbook, 2000. 